\title{
Application of Grey Relational Analysis in Appraisal of Industrial Economic Benefits
}

\author{
Yan Zhang \\ College of Economics and Management, \\ Hebei University of Science and Technology, \\ Shijiazhuang 050018, China \\ zywoman_80@126.com

$$
\text { Chang Wang }
$$ \\ College of Economics and Management, \\ Hebei University of Science and Technology, \\ Shijiazhuang 050018, China \\ 386868735@qq.com
}

\begin{abstract}
This article focuses on the research on the gray relational analysis of this multi-index comprehensive evaluation method, and the application of this method is applied to the evaluation of industrial economic benefits in western region of China. According to the model method, the evaluation objects can be arranged in the sequence based on the pros and cons, eventually the empirical results and the economic reality of western provinces is basically consistent. The result shows that this method can deal with the complicated and multi-hierarchy problem with insufficient information and it is of good maneuverability.
\end{abstract}

Keywords-Grey relational analysis, Industrial economic benefits, Comprehensive evaluation, AHP, Western region.

\section{INTRODUCTION}

In 1982, DengJulong who is the professor in Huazhong University of Science first put forward the concept of grey system, and established the grey system theory. Then, the grey system theory has been studied extensively, and gained success in many areas. The grey system theory argues that people has a wide gray side, namely the incompleteness and uncertainty of information, when understanding the objective things, thus which is formed by the objective things is a grey system. People also have a gray recognition on the comprehensive evaluation of the object, so we can study the comprehensive evaluation by means of the theory of gray system.

Grey system theory proposed a new method of analysis, namely the systematic relational analysis method. The problem of grey comprehensive evaluation is mainly discussing the grey relational analysis, this is to measure the relevancy between factors according to the degree of similarity or dissimilarity between the development trend of factors. This article focuses on the research on the gray relational analysis of this multi-index comprehensive evaluation method, and we will apply this method to empirical research in China's western industrial economic

\author{
Yuanjie Li \\ College of Economics and Management, \\ Hebei University of Science and Technology, \\ Shijiazhuang 050018, China \\ 854763920@qq.com \\ Shaoxuan Han \\ College of Economics and Trade, \\ Agricultural University of Hebei, \\ BaoDing, China \\ 532599502@qq.com
}

evaluation in order to verify the effectiveness of the method and promotion.

Analytic hierarchy process ( AHP) is a multi-objective decision method presented by the operational research expert T.L.S aaty professor in the 1970 s which is a kind of combination of qualitative and quantitative, and quantifies the qualitative factors. It embodies the basic thinking of characteristics of man decision-making, namely, the decomposition - judgment - integrated. The core of the method which is more practical under the condition of the complex target structure and lack of necessary data, is to quantify the experience judgments from policymakers and experts, So as to provide the quantitative form of decisionmaking. Therefore, this method is suitable for the research of this article.

\section{THE BASIC PRINCIPLE OF GREY RELATIONAL ANALYSIS AND THE MODEL'S INTRODUCTION}

Grey relational analysis is a multivariate statistical analysis method, the basic idea is to determine the degree of correlation between the sequence of system characteristic and related factors according to the similarity degree of the geometry of the sequence curve, the closer the curve, the greater the degree of correlation between the system characteristic sequences and related factors, whereas the smaller.

To perform the correlation analysis, we must first identify the data sequence, namely what data can reflect the behavior characteristics of the system. When there's a system behavior in the data column, we can calculate the correlation degree based on the correlation formula. Correlation degree reflects the order that every evaluation object close to the ideal target sequence, and the evaluation object with the largest gray correlation is the best.

Grey relational analysis model:

Grey comprehensive evaluation is mainly based on the following model: $\mathrm{R}=\mathrm{E} \times \mathrm{W}$. In the formula, $\mathrm{R}=\left[\mathrm{r}_{1}, \mathrm{r}_{2}, \ldots \mathrm{rm}\right]^{\mathrm{T}}$ is a comprehensive evaluation result vector of $\mathrm{m}$ evaluated 
objects; $\mathrm{W}=\left[\mathrm{w}_{1}, \mathrm{w}_{2}, \ldots \mathrm{w}_{\mathrm{n}}\right]^{\mathrm{T}}$ is the weight vector of $\mathrm{n}$ evaluation indexes; $\mathrm{E}$ is the judgment matrix of each index,

$$
E=\left[\begin{array}{cccc}
\xi_{1}(1) & \xi_{1}(2) & \cdots & \xi_{1}(n) \\
\xi_{2}(1) & \xi_{2}(2) & \cdots & \xi_{2}(n) \\
\vdots & \vdots & \vdots & \vdots \\
\xi_{m}(1) & \xi_{m}(2) & \cdots & \xi_{m}(n)
\end{array}\right]
$$

$\xi_{i}(k)$ is the correlation coefficient of the $\mathrm{K}$ index and the $\mathrm{K}$ optimal index in the $\mathrm{i}$-th evaluated object.

Sort the list by the value of $\mathrm{R}$.

1) To determine the optimal index set

Let $F^{*}=\left[j_{1}^{*}, j_{2}^{*}, \cdots j_{n}^{*}\right], j_{k}^{i}$, is the optimal value of the $\mathrm{k}$-th index. Each index value of the optimal sequence can be the optimized value of the evaluated objects, also can be the optimal value that evaluator accepted. Select the optimal index set, and construct the matrix D:

$$
D=\left[\begin{array}{cccc}
j_{1}^{*} & j_{1}^{*} & \cdots & j_{1}^{*} \\
j_{1}^{1} & j_{2}^{1} & \cdots & j_{n}^{1} \\
\vdots & \vdots & & \vdots \\
j_{1}^{m} & j_{2}^{m} & \cdots & j_{n}^{m}
\end{array}\right]
$$

Above, $j_{k}^{i}$ is the original value of the $\mathrm{k}$-th index in the i-th program.

\section{2) To standardize the indexes}

Since the evaluation indexes usually have different dimension and order of magnitude, they cannot be directly compared. In order to guarantee the reliability of the results, regulating the handling of the original indexes is needed.

Set the variation range of K-th index as $\left[j_{k 1}, j_{k 2}\right], j_{k 1}$ is the minimum of $\mathrm{K}$-th index in the evaluated objects, $j_{k 2}$ is the maximum of $\mathrm{K}$-th index in the evaluated objects, can be the original value type in a dimensionless value type. The original value of the above formula can be turned into a dimensionless value by the following formula. $C_{k}^{i} \in(0,1)$

$$
C_{k}^{i}=\frac{j_{k}^{i}-j_{k 1}}{j_{k 2}-j_{k}^{i}}, i=1,2, \cdots m, k=1,2, \cdots, n
$$

Then $D \rightarrow C$ matrix:

$$
C=\left[\begin{array}{cccc}
C_{1}^{*} & C_{1}^{*} & \cdots & C_{1}^{*} \\
C_{1}^{1} & C_{2}^{1} & \cdots & C_{n}^{1} \\
\vdots & \vdots & & \vdots \\
C_{1}^{m} & C_{2}^{m} & \cdots & C_{n}^{m}
\end{array}\right]
$$

3) To calculate the results of comprehensive evaluation

According to the theory of grey system, $\left\{C^{*}\right\}=\left[C_{1}^{*}, C_{2}^{*}, \cdots, C_{n}^{*}\right]$ will be used as the reference sequence, $\{C\}=\left[C_{1}^{i}, C_{2}^{i}, \cdots, C_{n}^{i}\right]$ will be served as the comparable sequence, then calculate the correlation coefficient of the $\mathrm{K}$ index and the $\mathrm{K}$ optimal index in the $\mathrm{i}$ - th evaluated object by using the grey relational analysis method.

Namely

$$
\begin{aligned}
& \xi_{\mathrm{i}}(k)=\frac{\min _{i} \min _{k}\left|C_{k}^{*}-C_{k}^{i}\right|+\rho \max _{i} \max _{k}\left|C_{k}^{*}-C_{k}^{i}\right|}{\left|C_{k}^{*}-C_{k}^{i}\right|+\rho \max _{i} \max _{k}\left|C_{k}^{*}-C_{k}^{i}\right|}, \quad \text { in it } \\
& \rho \in(0,1) \text { and usually } \rho=0.5 .
\end{aligned}
$$

Thus there is the comprehensive evaluation results: $\mathrm{R}=\mathrm{E} \times \mathrm{W}$, that is,

$$
r_{i}=\sum_{k=1}^{n} W(k) \times \xi_{i}(k)
$$

4) To sort the list by relational degree

Sort the list by relational degree of the reference sequence and comparable sequence in descending order. If the relational degree $r_{i}$ is maximum, it shows that $\left\{C^{i}\right\}$ is the most close to the optimal index $\left\{C^{*}\right\}$, namely the i-th evaluated object is superior to the others, namely also the variation trend of reference sequence and comparable sequence is consistent.

Grey relational analysis is to reveal the strength of the relationship among factors, the final result is to sort the list among all comparable sequences by relational degree.

\section{APPLICATION EXAMPLE}

Industrial enterprise economic benefits is macro concept of the industrial economic operation quality, namely the economic efficiency and the material utility when industrial enterprise is engaged in the process of production and business operation activities. Because of the industrial economic benefits is a comprehensive concept, involving all aspects of industrial production and business activities, it is difficult to use a single economic indicator to reflect the overall qualitative and quantitative description, so we can according to the overall situation of the whole process of production of the industrial enterprises, basing on the grey relational analysis method, make a set of comprehensive evaluation and index system, then make a scientific and reasonable comprehensive evaluation and study from different aspects and different angles in the process of industrial enterprise production, so as to reflect the comprehensive connotation of economic benefits of industrial enterprise.

\section{A. Establishment of a comprehensive evaluation index system of industrial economic benefits}

Due to the different situations of industrial enterprises, constructing a comprehensive index system of industrial economic benefits should follow the following principles: scientific principle; objective principle; comparable principle; Practical principle; overarching principle.

\section{1) The setting of the index system}

According to the connotation of industrial enterprise economic benefits, we consider that we should consider various aspects from the industrial enterprises to set indexes, such as their profits ability, development ability, the ability to create value, debt liquidation ability, operation ability, production efficiency, production and marketing situation, in order to form a set of comprehensive evaluation index system of industrial economic benefits.

2) The function analysis of index 
According to the connotation of industrial enterprise economic benefits, we serve the Industrial economic benefits $A$, Profitability $B_{1}$, Development and operation ability $B_{2}$, Debt liquidity $B_{3}$ as the index system, including:

First, the evaluation index of Profitability $\mathrm{B}_{1}$ includes: Contribution rate of total assets $C_{1}$, Cost profit rate $C_{2}$, Rate of return on net assets $\mathrm{C}_{3}$, All personnel labor productivity $\mathrm{C}_{4}$. All the four indicators can fully reflect the profit ability and level which enterprise can achieve after putting the assets, personnel, cost of investment into operation, and it is also the major indexes that fully embodied the enterprise management level and performance.

Second, the evaluation index of Development and operation ability B2 includes: Capital increment rate $\mathrm{C}_{5}$, Industrial added value rate $\mathrm{C}_{6}$, Product sales rate $\mathrm{C} 7$, Turnover of current assets $C_{8}$. These four indicators are a measure of the added value which is created by the enterprise in per capita and the changes of the enterprise net assets, it is the main indicator to evaluate the enterprise's development potential and it also can judge whether development potential has the power.

Third, the evaluation index of Debt liquidity B3 includes: Asset liability ratio $\mathrm{C}_{9}$, Current ratio $\mathrm{C}_{10}$. These two indicators are to measure the status of security and risk about enterprise production and operation. No security profit can not achieve the goal of sustainable development of enterprises and it is a short-term behavior without strategic.

\section{B. Industrial economic benefits evaluation based on the gray relational analysis}

According to the available index data about 10 western provinces in the 2012 China statistical yearbook, we can find out the optimal reference data column. After putting the whole data into the grey relational analysis software, the software can come to the conclusion directly.

1) Weight analysis about every index, AHP software results are shown in the TABLE I:

TABLE I. WEIGHTS OF EACH INDEX

\begin{tabular}{|c|c|c|c|c|}
\hline $\mathbf{A}$ & $\mathbf{B}_{\mathbf{1}}$ & $\mathbf{B}_{\mathbf{2}}$ & $\mathbf{B}_{\mathbf{3}}$ & weights \\
\hline & 0.46 & 0.2211 & 0.3189 & 0.205022 \\
\hline $\mathbf{C}_{\mathbf{1}}$ & 0.4457 & 0 & 0 & 0.075624 \\
\hline $\mathbf{C}_{\mathbf{2}}$ & 0.1644 & 0 & 0 & 0.131008 \\
\hline $\mathbf{C}_{\mathbf{3}}$ & 0.2848 & 0 & 0 & 0.048346 \\
\hline $\mathbf{C}_{\mathbf{4}}$ & 0.1051 & 0 & 0 & 0.041987 \\
\hline $\mathbf{C}_{\mathbf{5}}$ & 0 & 0.1899 & 0 & 0.059365 \\
\hline $\mathbf{C}_{\mathbf{6}}$ & 0 & 0.2685 & 0 & 0.026819 \\
\hline $\mathbf{C}_{\mathbf{7}}$ & 0 & 0.1213 & 0 & 0.092928 \\
\hline $\mathbf{C}_{\mathbf{8}}$ & 0 & 0.4203 & 0.6667 & 0.212611 \\
\hline $\mathbf{C}_{\mathbf{9}}$ & 0 & 0 & 0.3333 & 0.106289 \\
\hline
\end{tabular}

2) Make the index value be dimensionless, the results are shown in the TABLEII:

TABLE II. DIMENSIONLESS RESULTS OF INDEXES

\begin{tabular}{|c|c|c|c|c|c|c|c|c|c|c|}
\hline Province & $\mathrm{C}_{1}$ & $\mathrm{C}_{9}$ & $\mathrm{C}_{8}$ & $\mathrm{C}_{2}$ & $\mathrm{C}_{7}$ & $\mathrm{C}_{5}$ & $\mathrm{C}_{4}$ & $\mathrm{C}_{6}$ & $\mathrm{C}_{10}$ & $\mathrm{C}_{3}$ \\
\hline SiChuan & 15.02 & 61.88 & 2.33 & 8.2 & 97.77 & 125.46 & 230451.52 & 31.36 & 98.5 & 20.28 \\
\hline GuiZhou & 14.93 & 65.15 & 1.78 & 11.74 & 95.32 & 120.4 & 146556.9 & 23.84 & 98.73 & 19.19 \\
\hline YunNan & 18.71 & 59.46 & 1.81 & 9.71 & 97.33 & 112.81 & 159894.09 & 17.75 & 102.12 & 14.97 \\
\hline XiZang & 4.93 & 25.44 & 0.65 & 14.59 & 107.3 & 109.37 & 75978.26 & 17.7 & 197.49 & 3.65 \\
\hline ShanXi & 18.72 & 57.05 & 1.76 & 18.24 & 96.82 & 123.67 & 243193.16 & 26.6 & 109.84 & 26.15 \\
\hline GanSu & 11.68 & 63.27 & 2.32 & 4.24 & 97.8 & 117.28 & 232933.87 & 21.57 & 97.31 & 10.12 \\
\hline QingHai & 13.11 & 60.74 & 1.68 & 15.91 & 95.5 & 104.86 & 164017.6 & 16.69 & 89.49 & 19.29 \\
\hline NingXia & 8.77 & 65.6 & 1.72 & 8.05 & 95.97 & 124.31 & 223047.3 & 26.72 & 89.16 & 12.42 \\
\hline XinJiang & 19.73 & 52.55 & 2.49 & 18.62 & 98.76 & 112.77 & 272756.2 & 23 & 93.23 & 23.5 \\
\hline ChongQing & 12.84 & 61.68 & 2.35 & 5.6 & 97.43 & 117.65 & 250245.47 & 29.61 & 104.97 & 16.21 \\
\hline $\begin{array}{c}\text { Reference } \\
\text { sequence }\end{array}$ & 19.73 & 18.62 & 26.15 & 272756 & 125.46 & 31.36 & 107.27 & 2.49 & 65.6 & 197.49 \\
\hline
\end{tabular}


3) After putting the relevant indicators'data of 10 provinces into grey relational software, it revealed the correlation coefficient values and the sequences which based on the Pros and cons as shown in the TABLE III:

TABLE III. CORRELATION COEFFICIENT VALUES AND SEQUENCE

\begin{tabular}{|c|c|c|c|c|c|c|c|c|c|c|}
\hline $\begin{array}{l}\text { Underlying } \\
\text { Index }\end{array}$ & $\begin{array}{c}\text { Chong } \\
\text { Qing }\end{array}$ & SiChuan & GuiZhou & YunNan & XiZang & ShanXi & GanSu & QingHai & NingXia & $\underset{\text { Jiang }}{\text { Xin }}$ \\
\hline $\mathrm{C}_{1}$ & 0.99992 & 0.99995 & 0.99994 & 0.99999 & 0.99983 & 0.99999 & 0.99991 & 0.99992 & 0.99987 & 1 \\
\hline $\mathrm{C}_{2}$ & 0.99985 & 0.99988 & 0.99992 & 0.9999 & 0.99995 & 1 & 0.99983 & 0.99997 & 0.99988 & 1 \\
\hline $\mathrm{C}_{3}$ & 0.99989 & 0.99993 & 0.99992 & 0.99987 & 0.99974 & 1 & 0.99982 & 0.99992 & 0.99984 & 0.99997 \\
\hline $\mathrm{C}_{4}$ & 0.99994 & 0.81492 & 0.45663 & 0.49094 & 0.33333 & 0.92517 & 0.83429 & 0.50262 & 0.76214 & 1 \\
\hline $\mathrm{C}_{5}$ & 0.99991 & 1 & 0.99994 & 0.99985 & 0.99982 & 0.99979 & 0.99991 & 0.99976 & 0.99999 & 0.99985 \\
\hline $\mathrm{C}_{6}$ & 0.99998 & 1 & 0.99991 & 0.99984 & 0.99984 & 0.99995 & 0.99989 & 0.99983 & 0.99995 & 0.9999 \\
\hline $\mathrm{C}_{7}$ & 0.99989 & 0.99989 & 0.99986 & 0.99989 & 1 & 0.99989 & 0.99989 & 0.99986 & 0.99987 & 0.9999 \\
\hline $\mathrm{C}_{8}$ & 1 & 1 & 0.99999 & 0.99999 & 0.99998 & 0.99999 & 1 & 0.99999 & 0.99999 & 1 \\
\hline $\mathrm{C}_{9}$ & 0.99996 & 0.99996 & 1 & 0.99994 & 0.99954 & 0.99991 & 0.99998 & 0.99995 & 0.99999 & 0.99986 \\
\hline $\mathrm{C}_{10}$ & 0.99894 & 0.99887 & 0.99887 & 0.9989 & 1 & 0.999 & 0.99885 & 0.99876 & 0.99876 & 0.9988 \\
\hline $\begin{array}{c}\text { Relational } \\
\text { degree } \mathbf{R}\end{array}$ & 0.99983 & 0.9909 & 0.97358 & 0.97523 & 0.9676 & 0.99625 & 0.9918 & 0.97577 & 0.98831 & 0.9899 \\
\hline Sequence & 1 & 4 & 9 & 8 & 10 & 2 & 3 & 7 & 6 & 5 \\
\hline
\end{tabular}

Form the calculation process and the results, we can see that because of its higher overall labor productivity rate, asset value, industrial added value rate, product sales rate and liquidity asset turnover, and the index values of Chongqing city are relatively close to the reference sequence, so it is ranked first; as to Tibet, all index values are low, and most were the lowest, so it is

From the results, according to the data of 2011, it can be seen in the 10 western provinces that the value of Chongqing is closest to the optimal reference sequence, ranked first, and followed by Shanxi, Gansu, Sichuan, Xinjiang, Ningxia, Qinghai, Yunnan, Guizhou and Tibet.

\section{CONCLUSIONS}

In this paper, we applied the gray relational analysis method of multi-index comprehensive evaluation to the industrial economic benefits evaluation in western region of China, the evaluation objects could be arranged in the sequence based on the Pros and cons according to the model method, eventually the empirical results and the economic reality of western provinces was basically consistent. The method overcomes the one-sidedness of the previous single index evaluation, and provides a scientific and practical approach for the industrial economic evaluation elsewhere with the guiding significance and reference value.

The example of verification indicates that the gray relational analysis method can deal with the complicated and multi-hierarchy problem with insufficient information and it is of good maneuverability. The evaluation method is objective and accurate, and it has the characteristics of simple operation and high efficiency. Large numbers of enterprise can be evaluated with the computer, so it is also an easy way to implement. ranked tenth. Thus, for an area, the content of science and technology of products, personnel and capital investment efficiency and sales ability are the main factors that decide the industrial economic benefits in the region, the results will provide important reference for the government and industries to make short-term development plans.

\section{REFERENCES}

[1] Lina Fu and Ling He, A Study of Low-carbon Eco-city Evaluation Based on Gray Correlation Analysis Method, Journal of Xiangtan university, vol.37, no.3, pp.31-35, 2013.

[2] Hongping Ma, Discussion on the comprehensive evaluation method and index system of industrial enterprise economic benefitss, China Collective Economy, vol.16, pp.86-87, 2011.

[3] Xuefeng Zhang, Application of principal component analysis based on SPSS in economic evaluation, Modern Business Trade Industry, no.11, pp.28-29, 2010.

[4] China Statistical Yearbook, China Statistical Press, 2012.

[5] Linling Zhang, Economic benefit evaluation on the provinces and cities of China's large and medium-sized industrial enterprises, Scientific Decision-Making, no.12, pp. 41-57, 2011.

[6] Hongping Ma, Discussion on the comprehensive evaluation method and index system of industrial enterprise economic benefits, China Collective Economy, no.16, pp. 86-87, 2011.

[7] Liyuan Chen, Discussion on appraisal system of enterprise economic benefit evaluation. Gansu Science and Technology Aspect, pp. 98-99, 2009.

[8] RuiMu, Jiatai Zhang, Research of hierarchy synthetic evaluation based on grey relational analysis, System Engineering Theory and Practice, vol.10, pp.125-130, 2008.

[9] Chan J W K, Tong TK L. Multi-criteria material selections and end-of-life product strategy: Grey relational analysis approach Materials and Design, vol.28, no.5, pp. 1539-1546, 2007.

[10] Dong Du, Modern comprehensive evaluation method and case selection. Beijng: Tsinghua University Press, 2008: 111-116 